Funding: The national congenital rubella surveillance programme was originally funded by the Medical Research Council and is currently funded by the Public Health Laboratory Service. The British Paediatric Surveillance Unit of the Royal College of Paediatrics and Child Health was supported by the Medical Research Fund of Children Nationwide at the time of the study.

Competing interests: None declared.

1 Hall SM, Nicoll A. The British Paediatric Surveillance Unit-a pioneering method for investigating the less common disorders of childhood. Child Care Health Dev 1998;24:129-43. (Report of a seminar held in June 1995.)

2 Thomas HIJ. Specific antibody avidity studies in clinical microbiology: past, present and future. PHLS Microbiology Digest 1995;12(2):97-102.

3 Sentinel surveillance shows small decline in MMR coverage. Commun Dis Rep CDR Wkly 1998;8(36):317,320.

4 Begg N, Ramsay M, White J, Bozoky Z. Media dents confidence in MMR vaccine. $B M J$ 1998;316:56.

5 Department of Health, Welsh Office, Scottish Office Department of Health, DHSS (Northern Ireland). Immunisation against infectious disease. London: HMSO, 1996.

(Accepted 28 October 1998)

\title{
Cohort study of bacterial species causing urinary tract infection and urinary tract abnormalities in children
}

\author{
Olli Honkinen, Olli-Pekka Lehtonen, Olli Ruuskanen, Pentti Huovinen, Jussi Mertsola
}

Department of

Paediatrics, Turku

University Hospital,

20520 Turku,

Finland

Olli Honkinen,

research fellow

Olli Ruuskanen,

professor

Jussi Mertsola,

consultant in

paediatric infectious

diseases

Laboratory of

Clinical

Microbiology, Turku

University Hospital

Olli-Pekka

Lehtonen,

laboratory director

National Public

Health Institute,

Turku Department,

Turku, Finland

Pentti Huovinen,

laboratory director

Correspondence to: Dr Mertsola

jussi.mertsola@utu.fi

BMJ 1999;318:770-1
Children with urinary tract infection often have anatomical or functional abnormalities in their urinary tract. Imaging studies are therefore recommended, especially for young children, after the first urinary tract infection. ${ }^{1-3}$ There is, however, considerable variation in clinical practice and some resistance to diagnostic imaging for childhood urinary tract infection. ${ }^{4}$ We conducted this study to find out whether an association exists between the bacterial species causing the first urinary tract infection and abnormal findings in subsequent imaging studies.

\section{Patients, methods, and results}

We examined retrospectively the hospital records of all children with a positive urine culture from a sample obtained by suprapubic aspiration (any growth) or catheterisation (growth of at least $10^{3}$ colony forming units/ml) during January 1980 to December 1994. Asymptomatic children and those who had been in hospital for more than 2 days before the specimen was obtained were excluded. Children with proved infection had intravenous pyelography (1980-3) or ultrasonography (1984-94) plus voiding cystourethrography (radiographic in boys and nuclear in girls) 1-2 months after the acute infection.
We identified 1237 positive urine samples. Of these, $942(76 \%)$ were obtained by suprapubic aspiration and $295(24 \%)$ by bladder catheterisation. There were 982 (79\%) cultures positive for Escherichia coli, 66 (5.3\%) for Enterococcus sp, 55 (4.4\%) for Klebsiella sp, $47(3.8 \%)$ for coagulase negative staphylococcus, 39 (3.2\%) for Proteus sp, and 48 for other species. Of the 207 patients with enterococcal, klebsiella, coagulase negative staphylococcal, or proteus infections, hospital records were available for 201 . Forty one patients were excluded (20 had asymptomatic bacteruria, seven had chronic urinary problems such as neurogenic bladder, and in 14 cases one or both of the urinary tract imaging studies were lacking). The urinary tract infection was the first in 92 of the remaining 160 children with infections other than $E$ coli.

We compared the results of these children with those of 92 age and sex matched children whose first urinary tract infection was caused by $E$ coli. Student's $t$ test was used to compare the mean serum $\mathrm{C}$ reactive protein values in the two groups. The frequency of abnormalities in the urinary tract was compared by Pearson's $\chi^{2}$ test or Fisher's exact test if the number of expected observations was five or less in at least one cell.

Age, sex, imaging results, and operations in children according to cause of first urinary tract infection. Values are numbers (percentages) unless stated otherwise

\begin{tabular}{|c|c|c|c|c|c|}
\hline & E coli & Proteus & Klebsiella & Enterococcus & $\begin{array}{l}\text { Coagulase negative } \\
\text { staphylococcus }\end{array}$ \\
\hline No of patients & 92 & 26 & 26 & 26 & 14 \\
\hline Age <2 years (boys/girls) & $39 / 19$ & $12 / 2$ & $12 / 7$ & $11 / 8$ & $4 / 2$ \\
\hline Aged $\geqslant 2$ years (boys/girls) & $17 / 17$ & $7 / 5$ & $3 / 4$ & $6 / 1$ & $1 / 7$ \\
\hline Mean (SD) C reactive protein $(\mathrm{mg} / \mathrm{l})$ & $\begin{array}{l}69(47) \\
(\mathrm{n}=74)\end{array}$ & $\begin{array}{c}23(24)^{\star \star \star} \\
\quad(n=16)\end{array}$ & $\begin{array}{l}83(62) \\
(n=16)\end{array}$ & $\begin{array}{l}88(66) \\
(\mathrm{n}=23)\end{array}$ & $\begin{array}{c}39(53) \\
(n=9)\end{array}$ \\
\hline Reflux & $30(33)$ & $2(8)^{*}$ & $16(62)^{\star \star *}$ & $16(62)^{\star *}$ & $5(36)$ \\
\hline Grade $1-3$ & 26 & $1^{\text {** }}$ & 9 & 9 & 3 \\
\hline Grade 4-5 & 4 & 1 & $7^{* *}$ & $7^{\star *}$ & 2 \\
\hline Obstruction & $1(1)$ & 0 & $4(15)^{\star \star}$ & $3(12)^{\star}$ & $2(14)^{\star}$ \\
\hline Other anatomical abnormalities $\dagger$ & $4(4)$ & 0 & $2(8)$ & 0 & $1(7)$ \\
\hline Children with abnormalitiesł & $32(35)$ & $2(8)^{* *}$ & $18(69)^{* *}$ & $17(65)^{\star *}$ & $6(43)$ \\
\hline Operation or injection therapy for reflux & $7(8)$ & $2(8)$ & $10(38)^{\star \star \star *}$ & $12(46)^{\star \star \star}$ & $5(36)^{\star *}$ \\
\hline
\end{tabular}

${ }^{*} \mathrm{P}<0.05,{ }^{* *} \mathrm{P}<0.01,{ }^{* * *} \mathrm{P}<0.001$ compared with $E$ coli infections.

†These patients had ureter duplex, except patient with staphylococcus who had a polycystic kidney.

$\ddagger$ Some patients had both vesicoureteral reflux and other anatomical abnormalities. 
The table shows the characteristics of the 184 patients and findings in the imaging studies. There were significantly more abnormalities among children with enterococcal, klebsiella, or coagulase negative staphylococcal infections than in children infected with $E$ coli. The rate of corrective surgical procedures was also substantially higher in these patients. Only two abnormalities were diagnosed in children with proteus infection.

\section{Comment}

Our results agree with earlier studies showing that about $80 \%$ of urinary tract infections are caused by $E$ coli and that vesicoureteral reflux is found in about a third of children with infections caused by $E$ coli. ${ }^{3}$ We also found that when the first infection was caused by klebsiella or enterococcus the rate of vesicoureteral reflux was almost double and that surgical procedures were four times more common in children with infections caused by these organisms than in those with infections caused by $E$ coli.

$E$ coli lacking putative virulence factors such as galgal specific adhesins are overrepresented in patients with pyelonephritis associated with vesicoureteral reflux. ${ }^{35}$ Similarly, in children with acute pyelonephri- tis, renal scarring is significantly more common in those infected with non- $E$ coli organisms ${ }^{3}$ and with $E$ coli strains that do not possess certain virulence determinants. ${ }^{5}$ The bacteria probably do not need special virulence properties if the host has an abnormality such as vesicoureteral reflux.

Contributors: $\mathrm{OH}$, the principal investigator for the study, was involved in the data collection, documentation and analysis $\mathrm{O}-\mathrm{PL}$ and $\mathrm{PH}$ organised the collection and analysis of the microbiological data. OR initiated the research and participated with JM in the analysis and interpretation of the clinical data. The paper was written jointly by OH, O-PL and JM. OH and JM are guarantors of the study

Funding: Paediatric Research Foundation and Academy of Finland.

Competing interests: None declared.

1 Working party report. Guidelines for the management of acute urinary tract infection in children.J R Coll Physicians Lond 1991;25:36-42.

2 Smellie JM, Ridgen SPA, Prescod NP. Urinary tract infection: a comparison of four methods of investigation. Arch Dis Child 1995;72:247-50.

3 Rushton HG. Urinary tract infections in children; epidemiology, evaluation, and management. Pediatr Clin North Am 1997;44:1133-69.

4 Dick PT, Feldman W. Routine diagnostic imaging for childhood urinary tract infections: a systematic overview. J Pediatr 1996;128:15-22.

5 De Man P, Claeson I, Johanson I, Jodal U, Svanborg Eden C. Bacterial attachment as a predictor of renal abnormalities in boys with urinary tract infection. J Pediatr 1989;115:915-22.

(Accepted 9 November 1998)

\section{Drug points}

\section{Severe ergotism associated with interaction between ritonavir and ergotamine}

Lucas Liaudet, Thierry Buclin, Christian Jaccard, Philippe Eckert, Critical Care Division, Department of Internal Medicine (Service B), University Hospital, 1011 Lausanne, Switzerland

Ergotism is a severe complication of chronic abuse or acute intoxication with ergot derivatives. Occasional cases have been reported in patients taking usual doses of ergot combined with drugs that interact with it. ${ }^{12}$ We report a case of severe ergotism associated with the anti-HIV drug ritonavir.

A woman aged 28 who was positive for HIV infection was treated with anti-HIV tritherapy: stavudine $(40 \mathrm{mg} / 12$ $\mathrm{h})$, didanosine $(200 \mathrm{mg} / 12 \mathrm{~h})$, and ritonavir (600 mg/12 h). She also received fluoxetine $(20 \mathrm{mg} / 24 \mathrm{~h})$ for depressed mood. Five days before admission she had begun to take a combination drug $(0.3 \mathrm{mg}$ ergotamine tartrate, $0.2 \mathrm{mg}$ belladonna extract, and $20 \mathrm{mg}$ phenobarbital) twice daily for gastric discomfort. On the day before admission she developed painful sensations in both legs. On admission, her four extremities were pale, cold, and pulseless. A Doppler examination showed diffuse arterial spasms affecting the aorta and the femoral and humeral arteries; distal pulses were absent. Treatment with intravenous sodium nitroprusside, heparin, and morphine was started. Peridural anaesthesia was needed for intractable pain. After 3 days she developed cyanosis and oedema in both legs. Despite the addition of intravenous nifedipine, iloprost, and nitrates, she developed bilateral gangrene of the toes, necessitating transmetatarsal amputation 5 weeks later.

This patient developed severe ergotism after taking $3 \mathrm{mg}$ ergotamine over 5 days, a low dose in terms of the recommended safe dosage of ergot (up to $6 \mathrm{mg}$ a day or $10 \mathrm{mg}$ a week during chronic administration). We speculate that an interaction between ritonavir and ergotamine was responsible for this case. Indeed, ritonavir is a potent inhibitor of cytochrome $P$-450 isoenzymes, mainly CYP3A $4,{ }^{3}$ which is responsible for the metabolism of ergot. ${ }^{1}$ Thus, ergot concentrations probably increased to toxic amounts in our patient because ritonavir inhibited ergotamine metabolism. Fluoxetine, another inhibitor of cytochromes, might also have played some part by blocking supplementary metabolic pathways. This interaction between ergot derivatives and ritonavir has been described in the technical information provided by the manufacturer, ${ }^{4}$ and another case of ergotism has been reported in a patient with AIDS who received both ritonavir and ergotamine. ${ }^{5}$

Doctors should be aware of this harmful interaction, and any administration of ergot alkaloids should be discontinued when ritonavir treatment is started in patients with HIV infection.

1 Horowitz RS, Dart RC, Gomez HF. Clinical ergotism with lingual ischemia induced by clarithromycin-ergotamine interaction. Arch Intern Med 1996;156:456-8.

2 Bongard $\mathrm{O}$, Bounameaux $\mathrm{H}$. Severe iatrogenic ergotism: incidence and clinical importance. Vasa 1991;20:153-6.

3 Heylen R, Miller R. Adverse effects and drug interactions of medication commonly used in the treatment of adult HIV positive patients (part 2). Genitourin Med 1997;73:5-11.

4 Abbott Laboratories. Norvir (technical information). Chicago, IL: Abbott Laboratories, 1997

5 Caballero-Granado FJ, Viciana P, Cordero E, Gomez-Vera MJ, del Nozal M, Lopez-Cortes LF. Ergotism related to concurrent administration of ergotamine tartrate and ritonavir in an AIDS patient. Antimicrob Agents Chemother 1997;41:1207. 